\title{
Can Collaborative Innovation Constrain Ecological Footprint? Empirical Evidence From Guangdong- Hong Kong-Macao Greater Bay Area, China
}

\section{Xiaojun You}

Fujian Normal University https://orcid.org/0000-0002-4045-1506

\section{Qixiang Li}

Fujian Normal University

Kyle M. Monahan

Tufts University

Fei Fan

Wuhan University

\section{Haiqian Ke}

Wuhan University

Na Hong ( $\sim$ hongna305@126.com )

Shanghai Lixin University of Accounting and Finance

\section{Research Article}

Keywords: ecological footprint, collaborative innovation, eco-environment preservation, Empirical evidence, threshold regression model, Guangdong-Hong Kong-Macao Greater Bay Area (GBA)

Posted Date: November 22nd, 2021

DOl: https://doi.org/10.21203/rs.3.rs-966745/v1

License: (9) This work is licensed under a Creative Commons Attribution 4.0 International License. Read Full License

Version of Record: A version of this preprint was published at Environmental Science and Pollution Research on March 18th, 2022. See the published version at https://doi.org/10.1007/s11356-022-196483. 
1 Can collaborative innovation constrain ecological footprint?

2 Empirical evidence from Guangdong-Hong Kong-Macao Greater Bay

3 Area, China

4 Xiaojun You ${ }^{\mathrm{a}, \mathrm{b}}$, Qixiang Li ${ }^{\mathrm{a}}$, Kyle M. Monahan ${ }^{\mathrm{c}}$, Fei Fan ${ }^{\mathrm{d}, \mathrm{e}}$, Haiqian Ke $\mathrm{Ke}^{\mathrm{d}, \mathrm{e}}$

5 and $\mathrm{Na} \mathrm{Hong}{ }^{\mathrm{f} *}$

6

7

a School of Geographical Sciences, Fujian Normal University, Fuzhou 350007, China;

8

b Institute of Geographical Research, Fujian Normal University, Fuzhou 350007, China

9 c Data Lab, Tufts Technology Services, Tufts University, Medford, Massachusetts 02155, USA

10 d Institute of Central China Development, Wuhan University, Wuhan 430072, China

11 e Institute of Regional and Urban-Rural Development, Wuhan University, Wuhan 430072, China

12

f School of Public Finance and Administration, Shanghai Lixin University of Accounting and Finance, Shanghai 201620, China

13

14

E-mail addresses: xiaojun_you@fjnu.edu.cn (X. You), qixiang_li2020@163.com(Q. Li), kyle.monahan@tufts.edu (K. Monahan),

15

ffan@whu.edu.cn (F. Fan), kehaiqian@whu.edu.cn $($ H. Ke)

16

*Correspondent author: Na Hong (E-mail:hongna305@126.com, Telephone: +86-13705977570; Fax: +86-591-83465214)

17 
18 Can collaborative innovation constrain ecological footprint?

19 Empirical evidence from Guangdong-Hong Kong-Macao Greater Bay

20 Area, China

Abstract: Constraining ecological footprint (EF) has become an important policy priority to reach the carbon neutrality goal and deal with environmental issues, as it represents the socio-economic pressures on the environment. Current studies on the impact of collaborative innovation (CI) on EF is insufficient, although CI contributes to scientific productivity which benefits the technological progress in clean technology. In addition, seen from different perspectives, whether $\mathrm{CI}$ is effective in reducing EF has remain controversial. To further clarify this issue, this paper took Guangdong-Hong Kong-Macao Greater Bay Area (GBA) of China as a case, calculated EF between annual periods of 2008-2018 at the municipal level, measured CI from four dimensions and applied threshold regression models to compare the impact of CI on EF across different economic intervals. The findings showed that: the EF of GBA displayed an overall upward trend with prominent spatial heterogeneity during the study period. The impact of $\mathrm{CI}$ on EF presented a double-threshold effect when examined with different indicators. Among which, the flow of scientific personnel and capital boosted EF, which intensified with economic development; while collaboration in technology exerted significant inhibitory effects on EF, and the influence of inter-city knowledge collaboration was limited. This might inspire policymakers to adopt sustainable strategies depending on the type of $\mathrm{CI}$ and the economic status of the city to constrain the growth of EF, thus minimizing impacts of human activities on the environment.

38 Keywords: ecological footprint; collaborative innovation; eco-environment preservation; Empirical evidence; threshold regression model; Guangdong-Hong Kong-Macao Greater Bay Area (GBA)

\section{Introduction}

Population expansion and rapid economic growth is usually accompanied by an increase in the consumption of resources. The impact exerted by human exploitation of goods and services on the ecosystem has become one of the most important challenges for environmental scientists, urban planners, and economists worldwide (Wang et al. 2020a), as the tension between ecological preservation and economic and population growth has intensified over time (Fan et al. 2021). Meanwhile, the ecological impacts from urban expansion (Yang et al. 2019), energy usage (Mulligan 2010), population growth (Khan et al. 2021), economic dynamics (Tang et al. 2015) have also highlighted the threats to the security. 
In addition to employing land use change, soil carbon storage or carbon dioxide emissions as proxies of these myriad impacts (Begum et al. 2018), ecological footprint (EF) proposed by Rees (1992) has been adopted to examine broader environmental impacts (Elias et al. 2015). EF measures the pressures of human activities on ecological resources available on the entire earth and indicates the anthropogenic pressure on the environment (Rees 1992). The lingering challenge of reduction of global carbon emissions and the resulting deficit in ecological resources, especially for the United States, China and other large economics (Khan et al. 2021, Shahzad et al. 2021, Tang et al. 2015), has prompted the research on the reduction of EF. Additionally, extensive urbanization in such rapidly growing countries has caused a large decline in available land resources (Wu \&Liu 2020), and it is critically important to find a sustainable path towards relieving the pressure on the global ecosystem. Therefore, revealing the rationale behind the dynamics of $\mathrm{EF}$ is poised to provide further information for policy formulation, and can help guide policymakers, researchers and ecological activists.

EF has been investigated alongside many factors, and the trends in increasing EF have been attributed to economic growth (Usman \&Hammar 2021), energy consumption (Danish \&Wang 2019), globalization (Ahmed et al. 2019), population expansion (Anser et al. 2021), development of tourism (Qureshi et al. 2019), transportation (McBain et al. 2018), disposable income (Asici \&Acar 2016, Uddin et al. 2017), infrastructure construction (Erdogan 2020) and food consumption (Goldstein et al. 2017), which are interlinked with $\mathrm{CO}_{2}$ emissions from the consumption of natural resources (Hassan et al. 2019). Meanwhile, the innovation-environment nexus has been extensively studied by many researchers. Innovation is generally reckoned to be the key to decreasing environmental degradation when economic development reaches a high-income stage (Kihombo et al. 2021). More specifically, green innovation drives the introduction and upgrades of green technologies, which can minimise the waste of ecological resources, monitor environmental impacts, control pollution and while increase the efficiency of using ecological resources, thus manage to constrain EF from both source side and product side of the production (Song et al. 2019). But question remains about the role of innovation. Some researchers agreed that technological innovation acts as an effective tool for reducing carbon emissions (Cheng et al. 2019), while others argued that its impact is significant in the short run but shows no effect in the long term (Yii \&Geetha 2017). Innovation activities have even contributed to carbon emissions and a twoway causal relationship between innovation and $\mathrm{CO}_{2}$ emissions was pointed out in some countries, if these activities were production-focus (Khattak et al. 2020). Moreover, researchers claimed that 
81 technological innovation only focuses on reducing carbon emissions instead of control damage on 82 biologically productive land and water, therefore exerts limited impact on EF (Destek \&Manga 2021). If 83 taking the innovation efficiency into consideration, it does not necessarily suppress EF, more showing 84 an inverse U-shaped relationship across space (Ke et al. 2020). It is seen that mixed results are 85 documented when examining the influence of innovation on EF in broader pictures.

Measured through the flow of scientific personnel, capital and knowledge, collaborative innovation (CI) denotes the flow of factors in the innovation activities (Shi et al. 2018). Such inter-regional flow will promote the regional innovation performance via knowledge spillover, agglomeration of innovation elements and the factor allocation optimization effect (Fan et al. 2019), thus benefit the evolution of green technology and improve energy efficiency. Although there have been heated discussions on the relationship between innovation and $\mathrm{EF}$, few have considered the role of $\mathrm{CI}$ in constraining EF and have not yet come to an agreement either. The role of CI exhibits discrepancy across different domains of CI.

93 Gauged by the flow of innovation capital, CI shows a negative "U" relationship with ecological efficiency when but presents a positive "U" relationship when gauged by the flow of innovation personnel at the regional scale (Wang et al. 2021). Therefore, when discussing the impact of CI on EF, it is necessary to evaluate CI from multiple perspectives to obtain more accurate results.

99 Greater Bay Area (GBA) stands out both in the economic growth and in the progress of innovation. GBA is now poised to be China's most innovative region with the fastest economic growth in the past decade,

101 and has shown a strong growth in innovative firms, economic growth, and entrepreneurship. However, such rapid growth makes the GBA more ecologically vulnerable (Wang et al. 2020b). Even though the

103 dilemma of economic expansion and combating increasing EF has been the challenge for regions like

104 GBA, it is yet empirically unclear if CI can be a desirable solution to reduce EF, which makes it a typical case to examine the relationship between $\mathrm{CI}$ and $\mathrm{EF}$. 


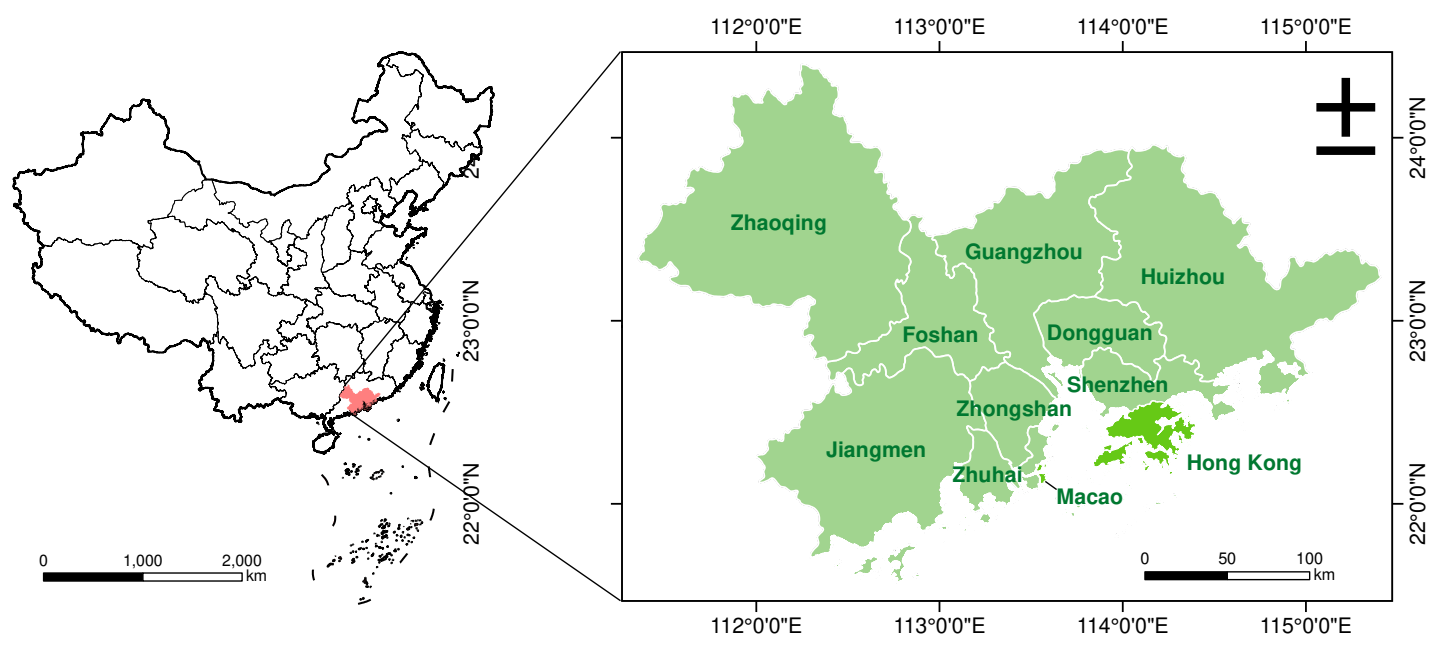

107 Fig. 1 Location of Guangdong- Hong Kong- Macao Greater Bay Area (GBA)

Based on the foregoing, this study depicted the spatial discrepancy and the evolution of EF in GBA, using 2008-2018 panel data from 11 cities within GBA, and further employed threshold regression model

110 to probe the impact of multiple domains of $\mathrm{CI}$ on EF across different economic stages. This paper thus

111 potentially contributes to present literature in two-fold. First, this study examined the nexus of CI and

112 EF with consideration of economic development, as innovation relates to potential ecological pressure

113 of growth at different income stages. Moreover, instead of using an artificially set threshold, threshold

114 regression model applied in this study can offer more precise evidence on locating multiple thresholds.

115 Second, this study investigated the impact of $\mathrm{CI}$ on $\mathrm{EF}$ from various dimensions that denote CI, including

116 the inter-city flow of scientific personnel, scientific capital, knowledge and technique, thus presenting a

117 more comprehensive scope to understand and compare their effects on EF. Hence, the empirical evidence

118 presented in this study is informative, shedding light on the dynamic relationship of EF with CI while

119 better serving the carbon neutrality goal and propelling the preservation of the environment.

\section{Literature review}

121 Researchers have explored the impact of technological innovation on ecological environment from

122 multiple perspectives. Initially, a focus on innovation within natural-resource based firms was

123 undertaken, finding the development of innovative sustainable products and eco-services could provide

124 a competitive edge for firms (Hart 1995). This led to a greater attention towards the impact of innovation

125 on environmentally focused products and companies, with the understanding that technological

126 innovation can reduce negative environmental impacts. 
Based on this agreement, Ahmad et al. (2020) found a stable, long-run impact of economic growth,

128 technological innovation and natural resources on EF. Song et al. (2019) argued that efficient use of 129 natural resources and sustainable EF can be achieved if technological innovation is enabled. In this way, 130 through careful management of innovation, industrial development and transformation, and development 131 of renewable energies, EF can be reduced. Employing Granger causality in G7 countries, Khan et al. 132 (2020) argued that any policies targeting environmental innovation prominently changes carbon 133 emissions and thus influencing EF. But researchers have not reached an agreement on the relationship 134 between innovation and EF. Recent work from Destek andManga (2021) found that technological 135 innovation reduced carbon emissions in the big emerging markets (BEM) countries, noting the 136 importance of finding the associated impact on EF. Through the second-generation panel data methods, 137 the empirical results from BEM countries confirmed the effective impact of technological innovation on 138 reducing carbon emissions but failed to prove the significant impact on EF if it does not involve progress 139 to reduce damage on biologically productive lands. Wang et al. (2019) found that due to the pressure to 140 grow regional economies in China, greater innovation was associated with higher pollution than the 141 national average, indicating that firms initially do not focus on development of human resources and 142 clean production strategies, but rather focus on how to improve the technology to increase overall firm 143 profits and competitiveness.

144 Considering the inverse relationship between economic development and EF, debates on whether 145 there exists a certain threshold above which the relationship between innovation and $\mathrm{EF}$ alters has been 146 popular. Dogan et al. (2019) investigated the validity of the hypothesis of an inverse between EF and 147 economic development among the MINT (Mexico, Indonesia, Nigeria, and Turkey) countries. This type 148 of inverse relationship is also known as the Environmental Kuznets Curve (EKC). The EKC hypothesis 149 conveys a notion that the environmental quality deteriorates during the initial stage of economic 150 development but improves when the economic growth passes a certain point (Apergis \&Ozturk 2015). 151 Khan et al. (2019) used an augmented mean group along with common correlated effect mean group 152 (CCEMG) estimation with panel heterogeneous causality to determine the relations between GDP, 153 energy and financial development within five Belt and Road Initiatives (BRI) regions and found support 154 for both the EKC with a U-shaped curve, and pollution haven hypothesis (PHH) among others. Al-mulali 155 et al. (2015) claimed an inverted U-shaped relationship between EF and GDP, which supported the EKC 156 hypothesis in upper middle-income and high-income countries but not in low-income and lower middle- 
income countries. The quadric term for economic growth showed a negative impact on EF, and the presence of the EKC hypothesis has been investigated with EF and a U-shaped relationship between real income and EF was found (Destek \&Sarkodie 2019, Destek et al. 2018).

Following the EKC framework, Sinha et al. (2020) conducted the bootstrap quantile regression analysis and found technological innovation boosted emissions in the Next 11 countries (N11) when it aims at achieving economic motives rather than ecological sustainability. Other researchers have found a similar relationship between innovation and EF within cities. To better understand the relationship between innovation efficiency and EF at different levels of economic development, Ke et al. (2020) used a generalized spatial two-stage least squares (GS2SLS) and threshold regression models across 280 Chinese cities, revealed an inverse U-shaped relationship within the eastern and central China, and the ability of innovation efficiency to suppress EF gradually enhanced with economic growth for the entire country. All in all, the presence of EKC suggests that the relationship between innovation and EF may diversify and fluctuate in the long run, its complexity echoes the need to examining it according to the different thresholds of economic development.

However, the literature regarding the relationship between CI and EF is scant. Collaborative innovation among innovation entities can be identified by the spatial interaction and connection among them (Wang et al. 2021), and is mainly realized through the flow of labour, capital and other innovative elements (Fan et al. 2019). Due to the compound meaning of CI, its impact on EF is less consistent, compared with the above analysis on innovation and EF. Both the undesirable and desirable effects of $\mathrm{CI}$ on EF have been found in the previous literature. For example, scientific labour is the scientific personnel and the sum of ideas, knowledge, skills, resources embodied in them (Lee \&Bozeman 2005). The flow of scientific labour among cities has intensified inter-city migration and resulted in the gathering of population, increasing energy consumption in transportation and food consumption in daily life, thereby affecting EF (Arouri et al. 2012). Similarly, the scientific capital flow among cities is normally accompanied with the construction of new research institutions, high-tech industries and their facilities, which may stimulate the growth of EF. Conversely, investment in cities could offer more access to efficient consumption of ecological resources (Baabou et al. 2017). Adedoyin et al. (2020) used Fully Modified and Dynamic Ordinary Least Squares models, found the selected EU-16 countries' research and development (R\&D) expenditure showed a negative significant relationship with EF in the long run, and the EKC existed. Zhang et al. (2021) applied the spatial generalized method of moments (GMM) at 

reducing carbon emission intensity, with energy intensity playing as the mediating effect. Moreover, this

189 study suggested that due to the regional economic and technological equity, the results showed spatial 190 heterogeneity between the inshore and the inland China, implying the threshold effect of economic

191 development. The above empirical studies give us a clue that when the scientific talents, funds and other resources flow into a certain space and innovation agglomeration reaches a certain threshold, it is

193 probable to induce technological breakthrough in various scientific fields, including fields that may 194 benefit the eco-environment preservation.

195 Besides the physical elements flowing among regions, the flow of innovative knowledge and 196 technology has been reckoned as another form of collaborative innovation, and is commonly represented 197 by scientific co-authorship in published articles and patents (Zhuang et al. 2021). Widely discussed in 198 literature using different methods and datasets, collaboration in science and technology is assumed to 199 facilitate the exchange of knowledge and skills, therefore enhance scientific productivity and create 200 innovative outputs (Bozeman et al. 2013, Wuchty et al. 2007). Ghita et al. (2018) expanded the 201 understanding of EF in the European context of information society, and argued that the innovation in 202 information technology may facilitate the scientific collaboration in cyberspace, which could reduce the 203 flow of labour, capital and equipment in the physical space as well as the EF attached in the flow; Khan 204 et al. (2020) reconfirmed the upgrading of green innovation in pollutant treatment, resource utilization 205 efficiency, industrial structure adjustment and other fields is beneficial to eco-environment protection 206 and sustainability, both of which may achieve a restraining effect on EF. But due to the undecidable 207 relationship between innovation and $\mathrm{EF}$, the impact of knowledge and technology flow requires further 208 attention.

209 Overall, viewing from multiple perspectives of $\mathrm{CI}$ and separately estimating their effects on $\mathrm{EF}$ with 210 consideration of EKC using threshold regression model can not only provide a more comprehensive and 211 precise way to understand the dynamic impact of CI on EF theoretically, but also offer practical 212 implications for policymakers in the environmental field. To accomplish this research goal, the rest of 213 this paper are ordered as follows: Section 3 presents an overview of data and methodology, while the 214 empirical results and discussion are reported in Section 4. The conclusion and policy implications are 215 provided in Section 5. 
3 Materials and Methods

\subsection{EF model}

218 Ecological footprint refers as "for how much area of biologically productive land and water an 219 individual, population, or activity requires to produce all the resources it consumes and to absorb the waste (carbon dioxide) it generates, using prevailing technology and resource management practices"

221 (Rudolph \&Figge 2017). EF objectively reflects the consumption intensity of human activities on the environmental resources by describing the bioproductive area required for human production (Świąder et al. 2020). EF was calculated as follows:

$$
\text { ef }=\frac{E F}{N}=\sum\left(\frac{c_{i}}{p_{i}} \cdot r_{i}\right) / N
$$

where, $e f$ is the ecological footprint per capita, $E F$ is the total ecological footprint, $N$ is the population of the city, $c_{i}$ is the consumption of the Commodity $i$ and $p_{i}$ is the average yielding capacity to produce Commodity $i . r_{i}$ is the land equivalence factor for the production of Commodity $i$, which represents the ratio of a given category's average global productivity divided by that of the entire planet's productive surfaces (Lin et al. 2018), and allows for the EF of different categories to be comparable across space.

EF can provide a quantitative basis for judging whether the production and consumption activities of a city are within the range of the ecological carrying capacity. Ecological carrying capacity refers to the total area of biological productive land that can be provided to human beings by a region. The calculation equation is as follows:

$$
e c=\frac{E C}{N}=\sum\left(A_{i} \cdot y_{i} \cdot r_{i}\right) / N
$$

235 where, $e c$ is ecological carrying capacity per capita, $E C$ is the total ecological carrying capacity, $A_{i}$ is the production area and $y_{i}$ is the yield factor, which denotes the ratio of a given category's average productivity of a city divided by that of the world.

Ecological deficit/surplus (ed/es) refers to the differences between ecological footprint and 239 ecological carrying capacity, which measures the supply and demand and sustainability of ecological services between human and land systems. When a region's $e c$ is less than $e f$, ecological deficit $(e d)$ 241 appears, indicating the supply of regional ecological resources neither meets the demands of social development nor bears the corresponding need for environmental remediation and renewal. Therefore,

243 the region may import resources from surrounding regions or even other faraway ones to satisfy the 244 increasing local demand for natural resources and energy. Conversely, ecological surplus (es) indicates 
that the supply of regional ecological resources is sufficient to meet the needs of human production (Guo

$\&$ Wang 2019). The equation for the $e d /$ es is as follows:

$$
e d / e s=e c-e f
$$

\section{$248 \quad 3.2$ CI indicator system}

249 Drawn from the existing literature, this paper measured CI among cities from four dimensions: the flow 250 of scientific personnel, the flow of scientific funds, the cooperation of scientific papers, and the 251 cooperation in patent application. The number of co-authored scientific papers and joint application patents represents the exchange of knowledge and technology, which were collected from the online databases (Table 1), while the flow of scientific personnel and scientific funds among cities were calculated by a gravity model. The gravity model of the scientific personnel flow can be expressed as:

$$
S p l_{i j}=\ln M_{i} \ln K_{j} R_{i j}^{-2}
$$

In Equation (4), GDP per capita of a city is used to characterize its attractiveness to the scientific personnel in other cities. $S p l_{i j}$ is the flow of scientific personnel from City $i$ to City $j, M_{i}$ represents the scientific personnel of City $i, K_{j}$ is the GDP per capita of City $j$, which represents the attractiveness of

259 City $j$, and $R_{i j}$ is the distance between the two cities. Based on Equation (4), the total flow of scientific personnel from City $i$ to the other cities could be calculated as:

$$
S p l_{i}=\sum_{j=1}^{n} S p l_{i j}
$$

where, $S p l_{i}$ is the total number of scientific personnel flowing from City $i$ to other cities, $n$ is the number of all cities and is equal to 11 in the GBA case.

Accordingly, the gravity model of the flow of scientific funds can be expressed as:

$$
S f l_{i j}=\ln N_{i} \ln N_{j} R_{i j}^{-2}
$$

where, $S f l_{i j}$ is the amount of scientific funds flowing from City $i$ to City $j$, while $N_{i}$ and $N_{j}$ denote the science and technology expenditure of City $i$ and City $j$, respectively. Similarly, the total amount of science and technology funds flowing from City $i$ to other cities can be measured as:

$$
S f l_{i}=\sum_{j=1}^{n} S f l_{i j}
$$

\subsection{Threshold regression model}

271 The threshold regression proposed by Hansen (1999) suggests that the effect of independent variable(s)

272 on the dependent variable may vary across different intervals, which provides a useful approach to 273 examine whether the impact of CI on EF would show a non-linear relationship at different stages of 
economic development. Compared with the traditional linear regression method, which cannot fully adjust for the dynamic changes of such impact, threshold regression model may be a more informative option. To this end, this paper firstly set a single-threshold regression model:

$$
\ln e f_{i t}=\alpha X_{i t}+\beta_{1} \ln c i_{i t} \times I\left(T_{i t} \leq \delta\right)+\beta_{2} \ln c i_{i t} \times I\left(T_{i t}>\delta\right)+C+\varepsilon_{i t}
$$

where, $\ln e f_{i t}$ is the dependent variable of the $i$-th region in Year $t, X$ is the control variable, $\ln c i_{i t}$ is the core independent variable, and $T_{i t}$ is the threshold variable (i.e., economic development). $\delta$ is a fixed threshold. $\alpha$ is the influence coefficient of $X_{i t}$ on the dependent variable, $\beta_{1}$ and $\beta_{2}$ are the influence coefficients of the core independent variables $\ln c i_{i t}$ when $T_{i t} \leq \delta$ and $T_{i t}>\delta$, respectively. $C$ is a constant term, $\varepsilon_{i t} \sim(0, \sigma)$ is a random disturbance term, and $I$ is an indicative function. The value is 1 when the condition is satisfied, otherwise, the value is 0 .

Equation (8) only assumes one threshold, but at the different stages of economic development, the actual impact of $\mathrm{CI}$ on EF may exist two or more thresholds. To make the threshold regression analysis more accurate, a double-threshold model and a triple-threshold model were set up, whose equations are shown in Equation (9) and Equation (10).

$$
\ln e f_{i t}=\alpha X_{i t}+\beta_{1} \ln c i_{i t} \times I\left(T_{i t} \leq \delta_{1}\right)+\beta_{2} \ln c i_{i t} \times I\left(\delta_{1}<T_{i t} \leq \delta_{2}\right)+\beta_{3} \ln c i_{i t} \times I\left(\delta_{2}<T_{i t}\right)+
$$

$C+\varepsilon_{i t}$

$$
\ln e f_{i t}=\alpha X_{i t}+\beta_{1} \ln c i_{i t} \times I\left(T_{i t} \leq \delta_{1}\right)+\beta_{2} \ln c i_{i t} \times I\left(\delta_{1}<T_{i t} \leq \delta_{2}\right)+\beta_{3} \ln c i_{i t} \times I\left(\delta_{2}<\right.
$$

$\left.T_{i t} \leq \delta_{3}\right)+\beta_{4} \ln c i_{i t} \times I\left(\delta_{3}<T_{i t}\right)+C+\varepsilon_{i t}$

where $\beta_{1}, \beta_{2}, \beta_{3}$ and $\beta_{4}$ denote the influence coefficients of the core independent variables $\ln c i_{i t}$ when $T_{i t}$ is at different intervals.

\subsection{Model construction and data description}

\subsubsection{Dependent variable}

Ecological footprint per capita ( $e f$ ) of each city in GBA was used as the dependent variable in threshold regression. According to the definition of EF, the usable land was divided into six categories for calculating the ecological production and the waste absorption, including cultivated land, grassland, forest land, water area, construction land and fossil energy land. For each city, EF of a single category was calculated by summing all products (such as milk, eggs, nuts, electricity, etc.) belonging to this category, and the total EF of a city was the EF of all categories combined. The larger EF value is, the more natural resources are consumed and the greater the ecological pressure is. 
In Equation (1), the average yielding capacity of China was used to measure $p_{i}$, while the

304 equivalence factor $r_{i}$ was referred to Wackernagel et al. (1999): cultivated land $=2.8$, grassland $=0.5$,

305 forest land $=1.1$, water area $=0.2$, construction land $=2.8$, and fossil energy land $=1.1$. The sources of

306 the required data are listed in Table 1.

$307 \quad 3.4 .2$ Independent variables

308 To depict the impact of CI on EF, four indicators were selected to represent CI, including the flow of

309 scientific personnel $\left(X_{1}\right)$, the flow of scientific funds $\left(X_{2}\right)$, the number of co-authored scientific papers

$310\left(X_{3}\right)$ and the number of joint application patents $\left(X_{4}\right) . X_{1}$ and $X_{2}$ were calculated according to Equation

311 (4) to Equation (7). Among which the scientific personnel and the scientific funds were measured by the

312 full-time equivalent of the R\&D personnel (units of 10,000 people) and the stock of R\&D expenditure

313 (units of 10,000 Yuan RMB) of a city, respectively, both were retrieved from China City Statistical

314 Yearbook. Meanwhile, the geographical distance $R_{i j}$ measured the linear distance between the geometric

315 center of two cities through their latitude and longitude coordinates, which were derived from National

316 Basic Geographic Information System’s 1:4000000 terrain database.

317 To include the co-authored scientific papers among cities both in English and in Chinese, $X_{3}$ was

318 calculated according to the search results from Web of Science database and China National Knowledge

319 Infrastructure database, both of which cover most of the published papers from GBA. $X_{4}$ was calculated

320 according to the Patent Cooperation Treaty (PCT) application records provided by the PATENTSCOPE

321 database of World Intellectual Property Organization.

\section{3.4.3 Threshold variable}

323 GDP per capita is an important indicator to estimate the economic development of a city. Therefore,

324 GDP per capita of 11 cities in GBA from 2008 to 2018 was regarded as the threshold variable $T_{i t}$, which

325 was obtained from China City Statistical Yearbook, Hong Kong Statistical Yearbook and Macao

326 Statistical Yearbook. The currency of GDP of Hong Kong and Macao was converted to Yuan RMB and

327 the foreign exchange rates of each year were retrieved from the World Bank, which was calculated as an

328 annual average based on monthly averages.

\section{3.4.4 Control variables}

330 To minimize the impact of factors other than the core independent variables on the threshold regression 331 results, this paper controlled other related variables that may affect EF. Considering that the size of the 
332 city's EF is the result of a combination of factors such as population, trade, investment and consumption,

333 etc., five other indicators were employed as the control variables $X_{i t}$. To be more specific, the number of 334 employed persons (Emp, units of 10,000 people) was adopted to measure the social development. The 335 actual utilized amount of foreign investment (FDI, units of 100 million USD) was applied to denote the 336 openness of the city. The total investment in fixed asset as a percentage of GDP (Fix, units of \%) was 337 adopted to characterize the development of infrastructures. The total retail sales of consumer goods (Con, 338 units of 10,000 Yuan RMB) were employed to evaluate the consumption level of the citizens. The 339 broadband subscribers of Internet (Int, units of 10,000 households) was used to depict the development 340 of information resources. These above-mentioned indicators were retrieved from China City Statistical 341 Yearbook.

342 Table 1 Variable selection and data resources

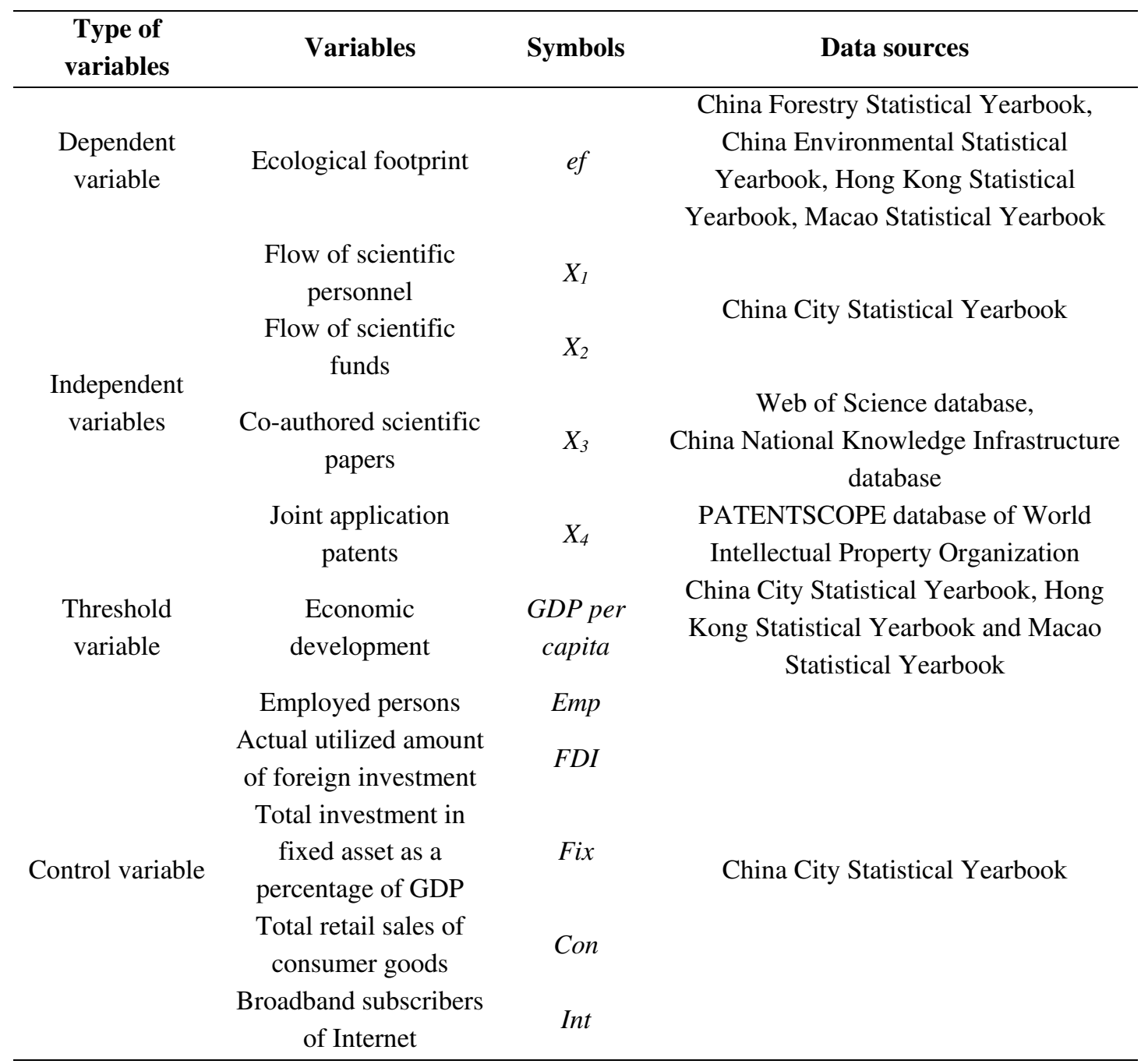




\section{4.1 The evolution of the ecological footprint in GBA}

345 The $e f$ of 11 cities in GBA from 2008 to 2018 was calculated (Fig. 2a), according to Formula (1). The 346 darker the color, the greater is EF and the higher the pressure on the ecological environment that the city 347 faces. The results showed that most cities in GBA confronted with a rise in EF during the study period, 348 among which EF of Dongguan and Jiangmen are the highest, exhibiting a similar trend and the largest increase. The ef of Zhuhai, Shenzhen, Foshan and Zhongshan have been in the middle group. These four cities were located around Dongguan and Jiangmen and have witnessed a slight increase from 2008 to 2016. The ef of Huizhou, Hong Kong, Zhaoqing, Macao and Guangzhou have been relatively low and remained stable. Notably, the ef of half of the cities (Jiangmen, Dongguan, Shenzhen, Zhuhai, Foshan and Huizhou) reached a clear turning point in 2016, after which showed a gradual decline.

According to Formula (2), the $e c$ of GBA was calculated (Fig. 2b), revealing that Hong Kong, Macao, Shenzhen and Dongguan have the highest ecological capacity in 2008. Meanwhile, the ec of the other 7 cities have remained relatively low from 2008 to 2016 but prominently climbed up afterwards, especially for Foshan, Zhaoqing, Zhuhai and Huizhou. Calculated by Formula (3), the ed/es of GBA was presented as Fig. 2c, showing that Macao and Hong Kong have maintained a large ecological surplus from 2008 to 2018, and Macao also experienced a growth in the ecological surplus. The ed/es of

360 Guangzhou from 2008 to 2018 is close to 0, while that of the other eight cities (Zhaoqing, Huizhou, 361 Shenzhen, Zhongshan, Foshan, Zhuhai, Dongguan and Jiangmen) have been negative, suggesting these 362 cities facing the ecological deficits. Moreover, the ecological overload of most cities has increased each 363 year, exerting a great pressure on the ecological environment, such as Zhongshan, Dongguan and 364 Shenzhen. On the contrary, cities like Foshan and Macao have achieved positive growth in ed/es, mainly 365 due to their substantial improvement of ecological capacity.

366 Overall, the ef, ec and ed/es of the 11 cities have fluctuated from 2008 to 2018 and been optimized 367 overall. Besides Macao and Hong Kong, which have showed ecological surplus, Guangzhou has a better 368 ed/es along with its fast economic development. While Shenzhen, Dongguan, Zhongshan and Hong Kong 369 were in the process of rapid economic growth from 2008 to 2018 , during which the ecological resources 370 were in great demand, increasing the pressure on the environment, thus creating a tension between 371 continued human growth and the ecological system. 

technology, the efficiency of utilizing the ecological resources has been improved and the ecological pressure of the 9 cities in Guangdong has gradually slowed down since 2016. At the end of 2015, Guangdong Province proposed to adhere to five principles-- innovation, coordination, green growth, development and shared benefits-- to lead and guide Guangdong's development in the thirteenth FiveYear Plan period, which contributes to the gradual decline of EF and the increase in the ecological carrying capacity in the 9 cities after 2016.
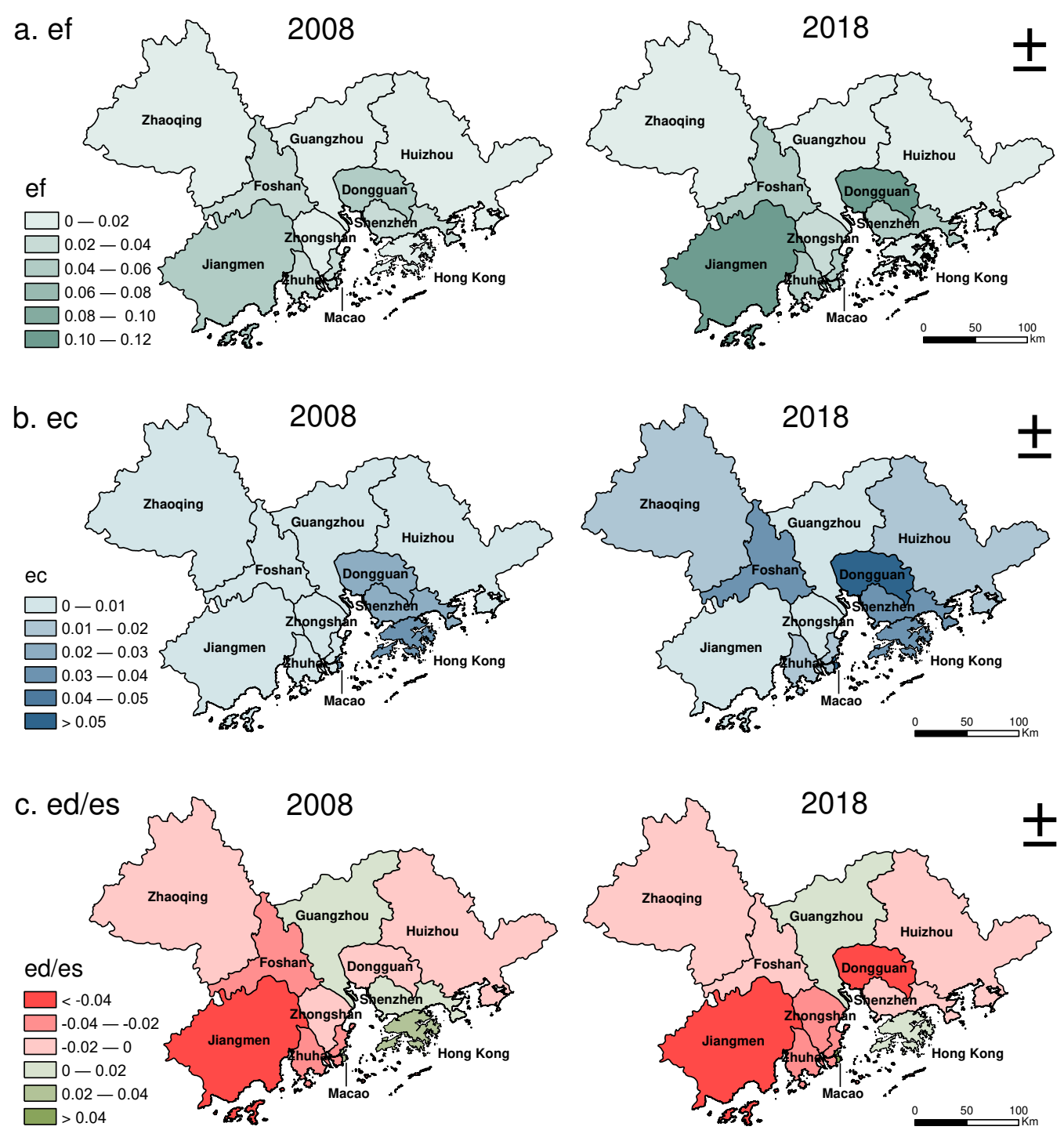

380 Fig. 2 Spatial evolution of (a) ef (b) ec (c) edles of 11 cities in GBA from 2008 to 2018

\section{$381 \quad 4.2$ The dynamic impact of collaborative innovation on ecological footprint}

382 Since the Hausman test was performed before the regression and the null hypothesis was rejected, the

383 fixed-effect model was applied in the threshold regression, with ef as the dependent variable and GDP 
384 per capita as the threshold variable. The results are shown in Table 2. $X_{I}$ passes the single-threshold and 385 double-threshold tests at a significance level of $1 \%$, but does not pass the triple-threshold test, indicating

$386 X_{1}$ rejects the triple-threshold hypothesis. $X_{2}, X_{3}$ and $X_{4}$ pass the single-threshold, double-threshold and 387 triple-threshold tests at different significance levels. Among which, $X_{2}$ passes the double-threshold test 388 at a significance level of $1 \%$, and $X_{4}$ passes the triple-threshold test at the $10 \%$ significance level but 389 passes other two tests at higher significance levels. Therefore, a double-threshold regression model was 390 chosen for the further analysis. Within the $95 \%$ confidence interval, the threshold estimates are presented 391 in Table 3.

392 Table 2 Threshold effect test

\begin{tabular}{ccccccc}
\hline Indicators of CI & \multicolumn{2}{c}{ Single-threshold test } & \multicolumn{2}{c}{ Double-threshold test } & \multicolumn{2}{c}{ Triple-threshold test } \\
\hline$X_{1}$ & $20.610^{* * *}$ & $(-0.002)$ & $10.560 * * *$ & $(-0.004)$ & 9.211 & $(-0.187)$ \\
$X_{2}$ & $22.280 *$ & $(-0.078)$ & $11.290 * *$ & $(-0.025)$ & $-7.460 * * *$ & $(-0.006)$ \\
$X_{3}$ & $43.054 * * *$ & $(0.000)$ & $33.616 * * *$ & $(-0.003)$ & $30.424 * * *$ & $(0.000)$ \\
$X_{4}$ & $30.515 * * *$ & $(-0.003)$ & $20.076^{* * *}$ & $(0.000)$ & $16.819 *$ & $(-0.065)$ \\
\hline
\end{tabular}

393 Note: The data in the table are the $F$ value corresponding to the threshold tests and the $p$ value are in parentheses. $394 * * *, * *$ and $*$ indicate significance at the levels of $1 \%, 5 \%$ and $10 \%$, respectively.

395 Table 3 The threshold estimate

\begin{tabular}{ccccc}
\hline Variables & $\delta_{1}$ & $95 \%$ confidence interval & $\delta_{2}$ & $95 \%$ confidence interval \\
\hline$X_{1}$ & 10.648 & $(10.631,10.656)$ & 10.883 & $(10.827,10.888)$ \\
$X_{2}$ & 10.883 & $(10.827,10.888)$ & 11.056 & $(11.030,11.073)$ \\
$X_{3}$ & 10.752 & $(10.739,10.800)$ & 11.614 & $(11.608,11.638)$ \\
$X_{4}$ & 10.849 & $(10.816,10.851)$ & 11.389 & $(11.374,11.408)$ \\
\hline
\end{tabular}

396 The regression results of threshold models are shown in Table 4. When the economic development 397 is below the first threshold of 10.648 (refers to GDP per capita of 42,108 Yuan RMB), the elasticity 398 coefficient of the flow of scientific personnel to EF is 0.0035 . When the economic development falls 399 between the first and second thresholds, the elasticity coefficient of the flow of scientific personnel rises 400 to 0.0045 and continued to go up to 0.0048 when the economic development exceeds the second 401 threshold of 10.883 (refers to GDP per capita of 53,263 Yuan RMB). Similarly, when the economic 402 development crosses the first threshold of 10.883 (GDP per capita of 53,263 Yuan RMB) and the second 403 threshold of 11.056 (GDP per capita of 63,323 Yuan RMB), the elasticity coefficient of the flow of 404 scientific funds to EF changes from 0.0012 to 0.0025 at the significance level of $1 \%$. 
With the improvement of economy, the stimulating impact of the flow of scientific personnel and

406 funds on EF becomes stronger. The economic growth not only increases the demand for the influx of 407 talents and capital to meet the need of innovation activities, trade, and other forms of economic 408 connection, but also brings with it the advancement of transportation and the efficiency of construction, 409 which are expected to reduce the difficulty of the migration of scientific resources among cities as well 410 as to provide sufficient facilities (including labs, equipment, highway network, broadband services, etc.) 411 for the innovation development. Innovation resources generally tend to agglomerate from less developed 412 cities to developed ones due to the Siphon Effect, during which the later cities may experience a surge 413 of consumption for energy, arable land, grassland, forest, water and other ecological resources, and the 414 rising of pollutants during the consumption, construction and migration, hereby prompting the growth of 415 EF. However, it is seen from the regression results that the growth rate of the elasticity coefficient slows 416 down while the economy continues to improve (Table 4). This may be since the inflow of scientific 417 resources begins to contribute to R\&D activities and the efficient use of ecological resources, restraining 418 the upward trend of EF.

419 Compared with $X_{1}$ and $X_{2}$, the intercity cooperation in publishing scientific papers and applying 420 patents have exerted differential impacts on EF. According to Model (3), the elasticity coefficient of co421 authored scientific papers stays slightly below 0 (significant at $1 \%$ and $5 \%$ level, respectively) until the economic development exceeds the second threshold of 11.614 (GDP per capita of 110,636 Yuan RMB), 423 indicating the cooperation in scientific papers having limited effects on EF. The publication of co424 authored papers among cities is usually viewed as the exchange and flow of tacit knowledge, such as 425 experience, ideas, regulation, etc., which can be carried out via internet with the popularization and upgrading of information technology, and it is not necessarily involve the face-to-face interaction and 427 other physical flow of resources, thus having minor impact on EF. Additionally, it normally takes at least 428 a year to apply the findings of a scientific paper to the new production that helps the ecological protection, 429 which explains the minimal effect of co-authored papers on EF in the short term.

432 Table 4 Model parameter estimation results

\begin{tabular}{lllll}
\hline Variables & Model (1) & Model (2) & Model (3) & Model (4)
\end{tabular}




\begin{tabular}{|c|c|c|c|c|}
\hline & $X_{1}$ & $X_{2}$ & $X_{3}$ & $X_{4}$ \\
\hline \multirow{2}{*}{$X\left(T_{i t} \leq \delta_{I}\right)$} & $0.0035 * * *$ & $0.0012 * * *$ & $-0.0000 * * *$ & $-0.0011 * *$ \\
\hline & $(3.73)$ & $(2.81)$ & $(-3.02)$ & $(-2.40)$ \\
\hline \multirow{2}{*}{$X\left(\delta_{1}<T_{i t} \leq \delta_{2}\right)$} & $0.0045 * * *$ & $0.0021 * * *$ & $-0.0000 * *$ & $-0.0020 * * *$ \\
\hline & $(5.05)$ & $(5.36)$ & $(-2.03)$ & $(4.82)$ \\
\hline \multirow{3}{*}{$X\left(T_{i t}>\delta_{2}\right)$} & $0.0048 * * *$ & $0.0025 * * *$ & $2.12 \mathrm{e}-06$ & $-0.0025 * * *$ \\
\hline & $(5.54)$ & $(6.80)$ & (1.27) & $(-6.35)$ \\
\hline & 0.0026 & $0.0091 * * *$ & $0.0101 * * *$ & $0.0112 * * *$ \\
\hline \multirow[t]{2}{*}{ Emp } & (1.19) & $(5.88))$ & (5.17) & $(-1.12)$ \\
\hline & $-0.0510 * * *$ & $-0.0424 * * *$ & $-0.0295 * *$ & $-0.0156 * * *$ \\
\hline \multirow[t]{2}{*}{$F D I$} & $(-5.25)$ & $(-4.76)$ & $(-2.65)$ & $(-3.82)$ \\
\hline & $0.0670 * * *$ & $0.0512 * * *$ & $0.0444 * * *$ & $0.0257 * * *$ \\
\hline \multirow[t]{2}{*}{ Fix } & (6.34) & $(5.25)$ & (3.60) & $(3.50)$ \\
\hline & $0.0353 * * *$ & $0.0261 * * *$ & $0.0332 * * *$ & $0.0169 * * *$ \\
\hline \multirow[t]{2}{*}{ Con } & (4.16) & $(3.28)$ & (3.10) & (4.09) \\
\hline & 0.0002 & -0.0001 & $-0.0000 * * *$ & -0.0002 \\
\hline Int & $(0.27)$ & $(-0.37)$ & $(-3.02)$ & $(-0.47)$ \\
\hline \multirow{2}{*}{$C$} & $0.6155^{* * *}$ & $0.5125^{* * *}$ & $0.2804 * *$ & $0.2226 * * *$ \\
\hline & $(5.40)$ & $(4.93)$ & $(2.25)$ & $(3.28)$ \\
\hline
\end{tabular}

433 Note: $t$-values are in parentheses, $* * *, * *$ and * indicate significance at the levels of $1 \%, 5 \%$ and $10 \%$, 434 respectively.

435 Meanwhile, it is worth noting that the growth of joint application patents among cities exerts a 436 negative double-threshold impact on $\mathrm{EF}$, and the greater the economic development, the stronger is the 437 suppression. The elasticity coefficient of the joint application patents to EF drops from -0.0011 to - 0.0020 438 then to -0.0025, with the economic development going up from below the first threshold of 10.849 (GDP per capita of 51,483 Yuan RMB) to over the second threshold of 11.389 (GDP per capita of 88,345 Yuan

440 RMB). At the early stages of economic development, the joint application patents mainly target at 441 achieving the economies of scale in production of the traditional manufacturing industries, as well as at 442 the traditional technology that may mildly decrease EF. As the knowledge and technology spillover from 443 developed cities to less ones accumulates, while the accuracy and complexity of the technology involved 444 in the joint application patents usually upgrades due to the need of economic growth and the high-tech 445 evolution of the industries, more efficient ways to allocate and consume resources are presented, 446 therefore is conducive to a strong inhibition of EF.

\section{Conclusion and policy remarks}

448 To understand the relationship between CI and EF, this study calculated EF in GBA from 2008 to 2018 449 and explored the evolution of EF, ecological capacity and ecological deficit/surplus at the city level. 
Furthermore, this study employed threshold regression models to investigate the dynamic impacts of CI

451 on EF at different levels of economic development and discussed the confounding factors. The key 452 conclusions are two-fold:

453 First, EF has exhibited spatial heterogeneity and an overall upward trend in GBA during the study 454 period. Despite the development in the economy, the EF of Hong Kong, Macao and Guangzhou have 455 stabilized at a relatively low level throughout the years, along with less developed cities like Zhaoqing 456 and Huizhou. On the contrary, with the economic boom during the recent years, Jiangmen and Dongguan 457 have experienced rapid increase in EF due to their strong demand for construction and rapid growth in 458 population density since 2008 . But thanks to the new development principles and the economic 459 transformation and upgrading strategy brought up during the thirteenth Five-Year Plan period, the EF of 460 most cities gradually declined since 2016 and the impact of human activities on the ecological environment in GBA have effectively been minimized.

Second, characterized by four different indicators, CI exerted a double-threshold impact on EF 463 which has continued to evolve with the development of the regional economies. To be more exact, the 464 flow of scientific labour and capital has stimulated EF by intensifying the intercity traveling and motivating the construction of scientific infrastructure; considering the joint application patents could be 466 done on the internet and could contribute to the eco-friendly technology at the same time, it has inhibitory effect on EF, and such effect has increased with the economic growth; but the influence of the co468 authored papers among cities has been limited, as the time lag exists between the publication of 469 knowledge and the application of green technology.

470 To summarize, CI influences EF throughout the different phrases of economic development, and its 471 non-linear impacts vary across different types of CI and may be altered by a variety of factors. The 472 dynamic relationship among $\mathrm{CI}, \mathrm{EF}$ and the economic growth is too complex to simply illustrate by the 473 EKC alone. Accordingly, the policymakers of the cities should implement the discrete eco-environmental 474 policies to balance the need of human activities and the reservation of ecological environment. Firstly, 475 although the transportation cost and waste from construction seems inherent to the flow of scientific 476 personnel and funds, cities can attract high-tech talents and high-end programs by offering preferential 477 policies in tax and rent. These policies can include relocation reimbursement, partially covering the per 478 diem expenses and guaranteeing the efficient management of scientific resources, etc., thus compensating the EF growth during the flow. Secondly, it is necessary to utilize the benefits of scale in 
scientific construction. By building research and industrial parks for innovative companies and

481 institutions, cities could promote the joint use of infrastructure and materials, therefore avoiding the

482 redundant construction of facilities and waste of ecological resources. This idea of multi-use buildings

483 has been investigated in urban planning contexts and is useful for promoting innovation and more

484 sustainable EF, especially at the early stage of innovation agglomeration. Thirdly, aiming at controlling

485 EF, cities should take advantages of the potential externalities and the technology transfer of joint

486 application patents to promote greater green development. The innovation and production in the clean

487 technology is not only the way to a greater optimization of energy infrastructure, more efficient use of

488 ecological resources, and less EF during the economic development, but also the path to more sustainable

489 relationship between humans and the environment which humans rely on.

\section{Declarations}

492 Ethics approval and consent to participate Not applicable.

493 Consent for publication Not applicable.

494 Availability of data and materials The datasets used and analysed during the current study are 495 available from the first author on reasonable request.

496 Competing interests The authors declare that they have no competing interests.

497 Funding This work was supported by the National Natural Science Foundation of China [Grant

498 Number 42001126]; and Fujian Planning Office of Philosophy and Social Science [Grant Number

499 FJ2020C035].

500 Authors' contributions Conceptualization, X.Y., F.F. and N.H.; Data curation, H.K. and Q.L.;

501 Funding acquisition, X.Y.; Methodology, X.Y., F.F. and H.K.; Project administration, X.Y., K.M. and

502 N.H.; Writing — original draft, X.Y., Q.L. and K.M.; Writing—review and editing, X.Y.

503 Acknowledgements We highly appreciate the constructive comments and suggestions from the

504 editors and reviewers that helped improved this manuscript.

\section{References}

Adedoyin F, Alola A, Bekun F (2020): An assessment of environmental sustainability corridor: the role of economic expansion and research and development in EU countries. Sci. Total Environ. 713, 136726. https://doi.org/10.1016/j.scitotenv.2020.136726 
Ahmad M, Jiang P, Majeed A, Umar M, Khan Z, Muhammad S (2020): The dynamic impact of natural resources, technological innovations and economic growth on ecological footprint: An advanced panel data estimation. Resources Policy 69. https://doi.org/10.1016/j.scitotenv.2020.136726

Ahmed Z, Wang Z, Mahmood F, Hafeez M, Ali N (2019): Does globalization increase the ecological footprint? Empirical evidence from Malaysia. Environmental Science and Pollution Research 26, 18565-18582. https://doi.org/10.1007/s11356-019-05224-9

Al-mulali U, Weng-Wai C, Sheau-Ting L, Mohammed AH (2015): Investigating the environmental Kuznets curve (EKC) hypothesis by utilizing the ecological footprint as an indicator of environmental degradation. Ecological Indicators 48, 315-323. https://doi.org/10.1016/j.ecolind.2014.08.029

Anser M, Yousaf Z, Nassani A, Abro M, Zaman K, Kabbani A (2021): Evaluating ecological footprints through inbound tourism, population density, and global trade. Pol. J. Environ. Stud. 30, 555560. https://doi.org/10.15244/pjoes/122445

Apergis N, Ozturk I (2015): Testing Environmental Kuznets Curve hypothesis in Asian countries. Ecological Indicators 52, 16-22. https://doi.org/10.1016/j.ecolind.2014.11.026

Arouri M, Youssef A, M'henni H, Rault C (2012): Energy consumption, economic growth and $\mathrm{CO}_{2}$ emissions in Middle East and North African countries. Energy Policy 45, 342-349. https://doi.org/10.1016/j.enpol.2012.02.042

Asici A, Acar S (2016): Does income growth relocate ecological footprint? Ecological Indicators 61, 707-714. https://doi.org/10.1016/j.enpol.2012.02.042

Baabou W, Grunewald N, Ouellet-Plamondon C, Gressot M, Galli A (2017): The Ecological Footprint of Mediterranean cities: Awareness creation and policy implications. Environmental Science \& Policy 69, 94-104. https://doi.org/10.1016/j.envsci.2016.12.013

Begum K, Kuhnert M, Yeluripati J, Ogle S, Parton W, Kader MA, Smith P (2018): Model based regional estimates of soil organic carbon sequestration and greenhouse gas mitigation potentials from rice croplands in Bangladesh. Land 7, 82. https://doi.org/10.3390/land7030082

Bozeman B, Fay D, Slade CP (2013): Research collaboration in universities and academic entrepreneurship: the-state-of-the-art. J Technol Transfer 38, 1-67. https://doi.org/10.1007/s10961-012-9281-8

Cheng C, Ren X, Wang Z (2019): The impact of renewable energy and innovation on carbon emission: an empirical analysis for OECD countries. Energy Procedia 158, 3506-3512. https://doi.org/10.1016/j.egypro.2019.01.919

Danish, Wang Z (2019): Investigation of the ecological footprint's driving factors: What we learn from the experience of emerging economies. Sust. Cities Soc. 49, 101626. https://doi.org/10.1016/j.scs.2019.101626

Destek M, Ulucak R, Dogan E (2018): Analyzing the environmental Kuznets curve for the EU countries: the role of ecological footprint. Environmental Science and Pollution Research 25, 29387-29396. https://doi.org/10.1007/s11356-018-2911-4

Destek M, Sarkodie S (2019): Investigation of environmental Kuznets curve for ecological footprint: The role of energy and financial development. Sci. Total Environ. 650, 2483-2489. https://doi.org/10.1016/j.scitotenv.2018.10.017

Destek M, Manga M (2021): Technological innovation, financialization, and ecological footprint: evidence from BEM economies. Environmental Science and Pollution Research 28, 2199122001. https://doi.org/10.1007/s11356-020-11845-2

Dogan E, Taspinar N, Gokmenoglu KK (2019): Determinants of ecological footprint in MINT countries. Energy environment 30, 1065-1086. https://doi.org/10.1177/0958305X19834279

Elias L, Lin D, Jon M, Jeanette H, Louisa P, Alessandro G (2015): Biodiversity Loss and the Ecological Footprint of Trade. Diversity 7, 170-191. https://doi.org/10.3390/d7020170

Erdogan S (2020): Analyzing the environmental Kuznets curve hypothesis: The role of disaggregated transport infrastructure investments. Sust. Cities Soc. 61, 102338. https://doi.org/10.1016/j.scs.2020.102338

Fan F, Lian H, Wang S (2019): Can regional collaborative innovation improve innovation efficiency? An empirical study of Chinese cities. Growth and Change 51, 440-463. https://doi.org/10.1111/grow.12346

Fan F, Lian H, Liu X, Wang X (2021): Can environmental regulation promote urban green innovation Efficiency? An empirical study based on Chinese cities. Journal of Cleaner Production 287, 125060. https://doi.org/10.1016/j.jclepro.2020.125060 
Ghita S, Saseanu A, Gogonea R, Huidumac-Petrescu C (2018): Perspectives of ecological footprint in European context under the impact of information society and sustainable development. Sustainability 10, 3224. https://doi.org/10.3390/su10093224

Goldstein B, Birkved M, Fernandez J, Hauschild M (2017): Surveying the Environmental Footprint of Urban Food Consumption. J. Ind. Ecol. 21, 151-165. https://doi.org/10.1111/jiec.12384

Guo S, Wang Y (2019): Ecological Security Assessment Based on Ecological Footprint Approach in Hulunbeir Grassland, China. International Journal of Environmental Research and Public Health 16, 4805. https://doi.org/10.3390/ijerph16234805

Hansen B (1999): Threshold effects in non-dynamic panels: Estimation, testing, and inference. Journal of Econometrics 93, 345-368. https://doi.org/10.1016/S0304-4076(99)00025-1

Hart S (1995): A natural-resource-based view of the firm. Academy of management review 20, 9861014. https://doi.org/10.5465/amr.1995.9512280033

Hassan S, Xia E, Khan N, Shah S (2019): Economic growth, natural resources, and ecological footprints: evidence from Pakistan. Environmental Science and Pollution Research 26, 29292938. https://doi.org/10.1007/s11356-018-3803-3

Ke H, Yang W, Liu X, Fan F (2020): Does Innovation Efficiency Suppress the Ecological Footprint? Empirical Evidence from 280 Chinese Cities. International Journal of Environmental Research and Public Health 17, 6826. https://doi.org/10.3390/ijerph17186826

Khan A, Chenggang Y, Hussain J, Bano S (2019): Does energy consumption, financial development, and investment contribute to ecological footprints in BRI regions? Environmental Science and Pollution Research 26, 36952-36966. https://doi.org/10.1007/s11356-019-06772-w

Khan I, Hou F, Le H (2021): The impact of natural resources, energy consumption, and population growth on environmental quality: Fresh evidence from the United States of America. Sci. Total Environ. 754, 142222. https://doi.org/10.1016/j.scitotenv.2020.142222

Khan Z, Ali S, Umar M, Kirikkaleli D, Jiao Z (2020): Consumption-based carbon emissions and international trade in $\mathrm{G} 7$ countries: the role of environmental innovation and renewable energy. Sci. Total Environ. 730, 138945. https://doi.org/10.1016/j.scitotenv.2020.138945

Khattak S, Ahmad M, Khan Z, Khan A (2020): Exploring the impact of innovation, renewable energy consumption, and income on CO2 emissions: new evidence from the BRICS economies. Environmental Science and Pollution Research 27, 13866-13881. https://doi.org/10.1007/s11356-020-07876-4

Kihombo S, Ahmed Z, Chen S, Adebayo TS, Kirikkaleli D (2021): Linking financial development, economic growth, and ecological footprint: what is the role of technological innovation? Environmental Science and Pollution Research, 1-11. https://doi.org/10.1007/s11356-021$\underline{14993-1}$

Lee S, Bozeman B (2005): The impact of research collaboration on scientific productivity. Social studies of science 35, 673-702. https://doi.org/10.1177/0306312705052359

Lin D, Hanscom L, Murthy A, Galli A, Evans M, Neill E, Mancini MS, Martindill J, Medouar F-Z, Huang S (2018): Ecological footprint accounting for countries: updates and results of the National Footprint Accounts, 2012-2018. Resources 7, 58. https://doi.org/10.3390/resources7030058

McBain B, Lenzen M, Albrecht G, Wackernagel M (2018): Reducing the ecological footprint of urban cars. Int. J. Sustain. Transp. 12, 117-127. https://doi.org/10.1080/15568318.2017.1336264

Mulligan S (2010): Energy, Environment, and Security: Critical Links in a Post-Peak World. Glob. Environ. Polit. 10, 79-100. https://doi.org/10.1162/GLEP_a_00032

Qureshi M, Elashkar E, Shoukry A, Aamir A, Mahmood N, Rasli A, Zaman K (2019): Measuring the ecological footprint of inbound and outbound tourists: evidence from a panel of 35 countries. Clean Technol. Environ. Policy 21, 1949-1967. https://doi.org/10.1007/s 10098-019-01720-1

Rees W (1992): Ecological footprints and appropriated carrying capacity. Environment and Urbanization 4, 120-130. https://doi.org/10.1177/095624789200400212

Rudolph A, Figge L (2017): Determinants of ecological footprints: what is the role of globalization? Ecological Indicators 81, 348-361. https://doi.org/10.1016/j.ecolind.2017.04.060

Shahzad U, Fareed Z, Shahzad F, Shahzad K (2021): Investigating the nexus between economic complexity, energy consumption and ecological footprint for the United States: New insights from quantile methods. Journal of Cleaner Production 279, 123806. https://doi.org/10.1016/j.jclepro.2020.123806

Shi H, Cui Y, Tsai S, Wang D (2018): The Impact of technical-nontechnical factors synergy on innovation performance: The moderating effect of talent flow. Sustainability 10, 693. https://doi.org/10.3390/su10030693 
Sinha A, Sengupta T, Alvarado R (2020): Interplay between technological innovation and environmental quality: formulating the SDG policies for next 11 economies. Journal of Cleaner Production 242, 118549. https://doi.org/10.1016/j.jclepro.2019.118549

Song M, Fisher R, Kwoh Y (2019): Technological challenges of green innovation and sustainable resource management with large scale data. Technological Forecasting and Social Change 144, 361-368. https://doi.org/10.1016/j.techfore.2018.07.055

Świąder M, Lin D, Szewrański S, Kazak JK, Iha K, van Hoof J, Belčáková I, Altiok S (2020): The application of ecological footprint and biocapacity for environmental carrying capacity assessment: A new approach for European cities. Environmental Science \& Policy 105, 56-74. https://doi.org/10.1016/j.envsci.2019.12.010

Tang X, McLellan B, Snowden S, Zhang B, Hook M (2015): Dilemmas for China: energy, economy and environment. Sustainability 7, 5508-5520. https://doi.org/10.3390/su7055508

Uddin G, Salahuddin M, Alam K, Gow J (2017): Ecological footprint and real income: Panel data evidence from the 27 highest emitting countries. Ecological Indicators 77, 166-175. https://doi.org/10.1016/j.ecolind.2017.01.003

Usman M, Hammar N (2021): Dynamic relationship between technological innovations, financial development, renewable energy, and ecological footprint: fresh insights based on the STIRPAT model for Asia Pacific Economic Cooperation countries. Environmental Science and Pollution Research 28, 15519-15536. https://doi.org/10.1007/s11356-020-11640-Z

Wackernagel M, Onisto L, Bello P, Linares AC, Falfan ISL, Garcia JM, Guerrero AIS, Guerrero CS (1999): National natural capital accounting with the ecological footprint concept. Ecological Economics 29, 375-390. https://doi.org/10.1016/s0921-8009(98)90063-5

Wang Q, Qu J, Wang B, Wang P, Yang T (2019): Green technology innovation development in China in 1990-2015. Sci. Total Environ. 696, 134008. https://doi.org/10.1016/j.scitotenv.2019.134008

Wang S, Jia M, Zhou Y, Fan F (2020a): Impacts of changing urban form on ecological efficiency in China: a comparison between urban agglomerations and administrative areas. Journal of Environmental Planning and Management 63, 1834-1856. https://doi.org/10.1080/09640568.2019.1689932

Wang S, Wang X, Lu F, Fan F (2021): The impact of collaborative innovation on ecological efficiency - empirical research based on China's regions. Technol. Anal. Strateg. Manage. 33, 242-256. https://doi.org/10.1080/09537325.2020.1812564

Wang Y, Zhou Q, Wang H (2020b): Assessing ecological carrying capacity in the Guangdong-Hong Kong-Macao Greater Bay Area based on a three-dimensional ecological footprint model. Sustainability 12, 9705. https://doi.org/10.3390/su12229705

Wu D, Liu J (2020): Spatial and temporal evaluation of ecological footprint intensity of Jiangsu Province at the county-level scale. International Journal of Environmental Research and Public Health 17, 7833. https://doi.org/10.3390/ijerph17217833

Wuchty S, Jones B, Uzzi B (2007): The increasing dominance of teams in production of knowledge. Science 316, 1036-1039. https://doi.org/10.1126/science.1136099

Yang Z, Chen Y, Wu Z, Qian Q, Zheng Z, Huang Q (2019): Spatial heterogeneity of the thermal environment based on the urban expansion of natural cities using open data in Guangzhou, China. Ecological Indicators 104, 524-534. https://doi.org/10.1016/j.ecolind.2019.05.032

Yii K, Geetha C (2017): The nexus between technology innovation and CO2 emissions in Malaysia: evidence from granger causality test. Energy Procedia 105, 3118-3124. https://doi.org/10.1016/j.egypro.2017.03.654

Zhang J, Yu H, Zhang K, Zhao L, Fan F (2021): Can innovation agglomeration reduce carbon emissions? evidence from China. International Journal of Environmental Research and Public Health 18, 382. https://doi.org/10.3390/ijerph18020382

Zhuang T, Zhao S, Zheng M, Chu J (2021): Triple helix relationship research on China's regional university-industry-government collaborative innovation: Based on provincial patent data. Growth and Change 00, 1-26. https://doi.org/10.1111/grow.12490 